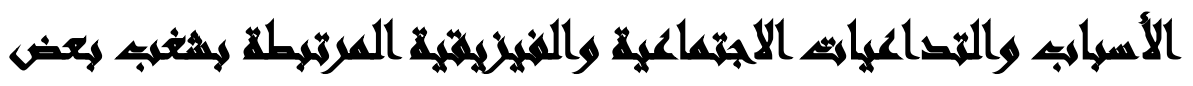

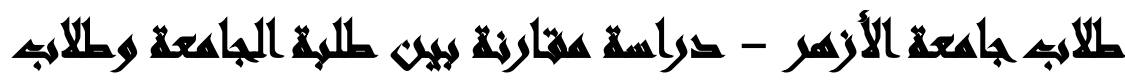 المقينية الجاهعية والأهر
}

[11]

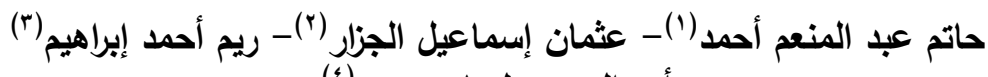

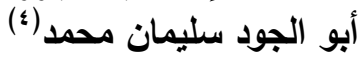

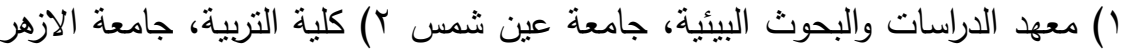
r) كلية التربية، جامعة حلوان ع ) الأزهر الثريف حامعة

\section{المستخليك}

هدفت الدراسة إلى الكثف عن الأسباب والتداعيات الاجتماعية والفيزيقية المرتبطة بشغب بعض طلاب جامعة الأزهر ، وكانت الدراسة مقارنة بين طلاب جامعة الأزهر (كطلاب الاب الابن

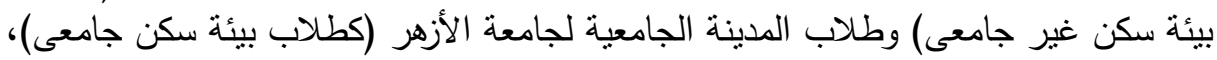

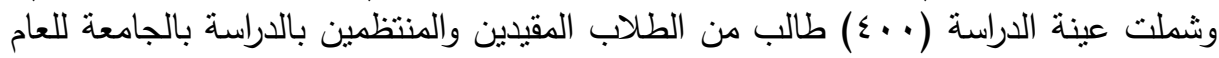

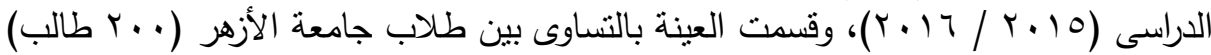
(من غير المقيمين بالسكن الجامعى)، وطلاب المدينة الجامعية لجامعة الأزهر ( ... ب طالب) (من المقيمين إقامة كاملة بالمدينة الجامعية).

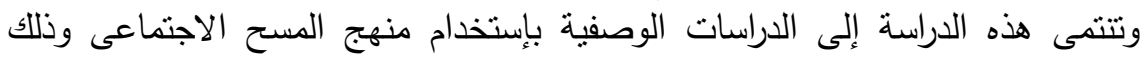

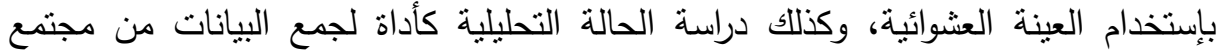

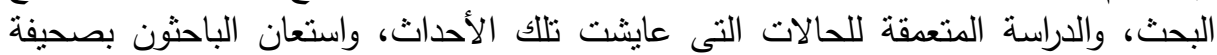

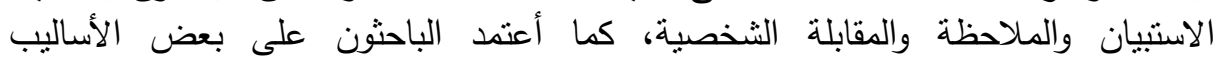

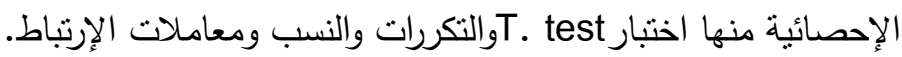

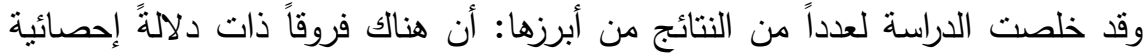

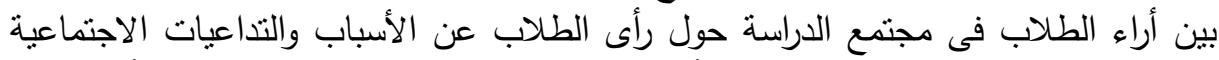

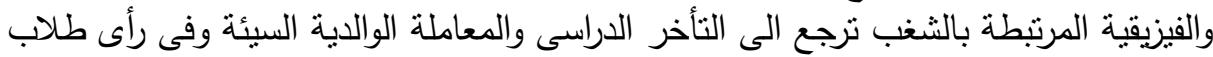

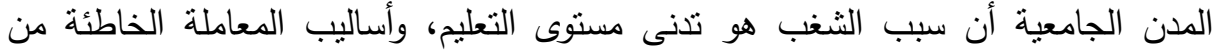

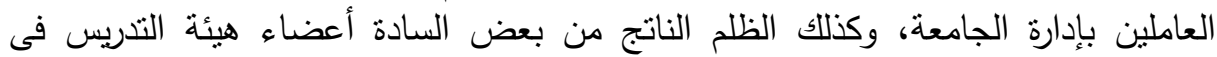
تصحيح أوراق الاجابة، والدرجات الضعيفة التى لا يستحقها الطلاب بعد جهد وتعب وكد في النى

$$
\text { المجلد الخامس والثلاثون، الجزء الثاني، سبتمبر } 7 \text { ا ـ ب }
$$


المادة التعليمية من وجهة نظرهم، وأن تجمع كل هذه الاسباب نسبب فى أحداث الثغب التى حدثت بالجامعة الأزهرية العريقة. أظهرت الدراسة أن هناك العديد من التداعيات الناتجة عن أحداث الثغب التى حدثت

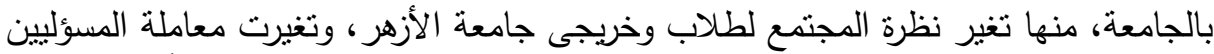

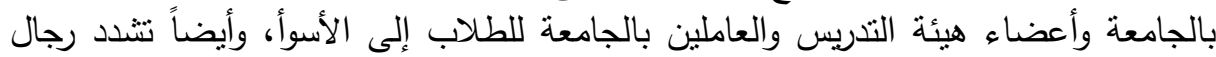

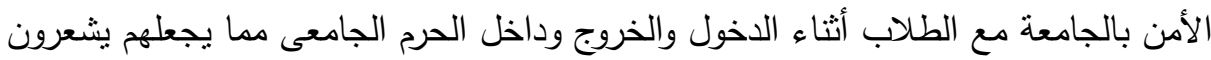

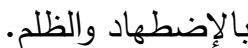
وتوصى الدراسة بعمل ندوات وحوارات بين المسؤليين بالجامعة وأعضاء هيئة التدريس للتخفيف من هذه الأسباب التى تسبيت في أعمال الثغب بات بالجامعة.

\section{$\sin$}

يقسم القرآن الكريم حياة الإنسان إلى مرحلتين للضعف بينهما مرحلة قوة، فى قوله تعالى

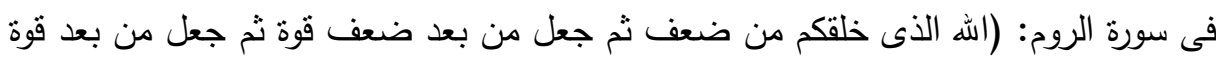

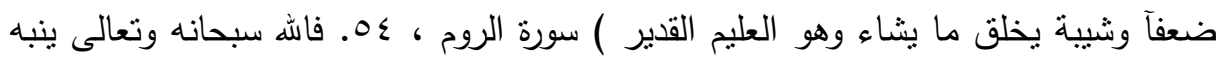

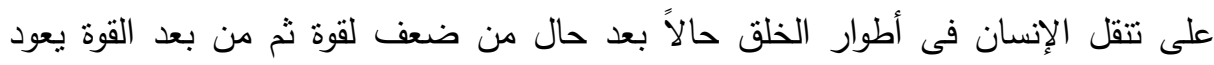

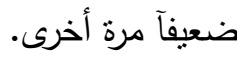

وتأسيساً على ما تقدم فسوف تقتصر دراستتا الحالية على مرحلة الثباب التى يعيش فيها غالبية طلاب الجامعات وهى مرحلة القوة والعنفوان وهى تتميز من حيث السمات الاجتماعية

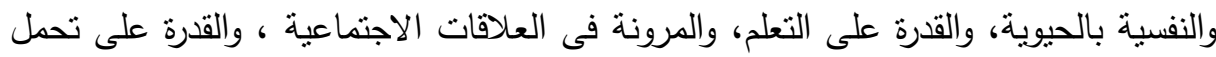

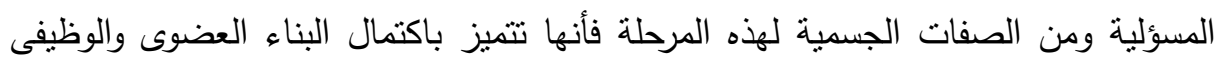
للمكونات الأساسية كالعضلات والغدد... إلخ. كما تتميز بالقابلية للعطاء والابتكار والمشاركة

$$
\text { فى إحداث التغيير فى المجتمع. }
$$

ويمتل الثباب قطاعاً مهماً فى البناء السكانى للمجتمع المصرى حيث تفيد أحدث

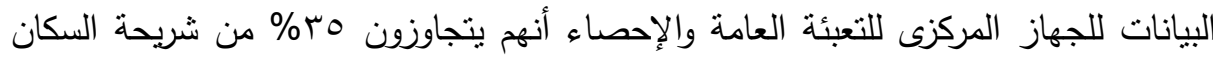

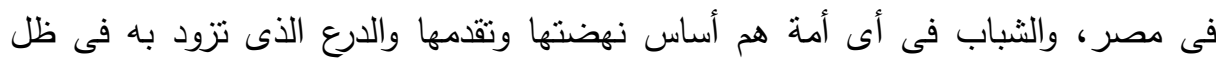
متغيرات وتطورات العصر المذهلة كالثورتين المعلوماتية والبيولوجية وهم الدليل الذى يمكن الاعتماد عليه فى التتبؤ بمستقبلها وعلى ذلك فإن مدى ما توجهه الأمة لشبابها من رعاية 
واهتمام إنما هو مقياس أساس تقدمها ونهضتها ليس فى الحاضر فحسب بل وفى المستقبل أيضاً. فعلى قدر ما يكون شباب الأمة من قوة وكفاءة وخلق وعلم يكون قدر الأمة من تقدم ونمانم

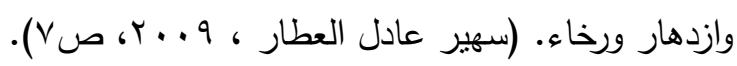

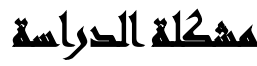

الثباب الجامعي هم الثريحة التى تسعي دائماً إلى التجديد والتحديث في المجتمع والتى أنى

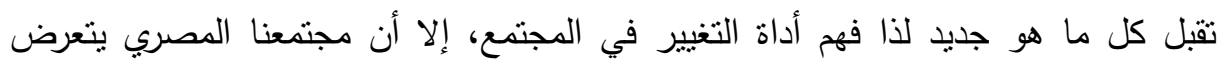

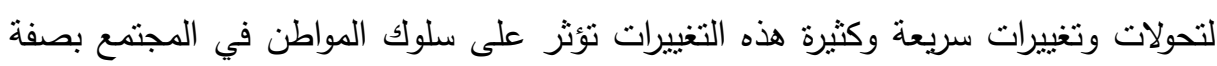

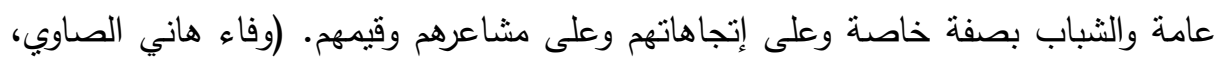

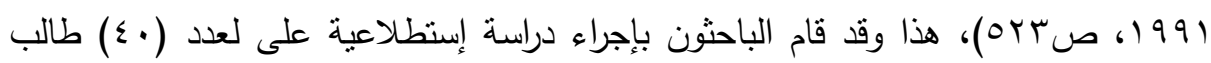

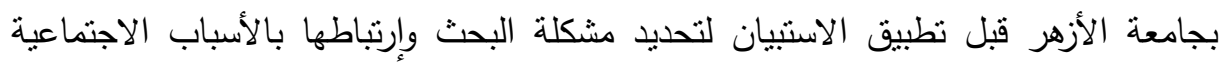

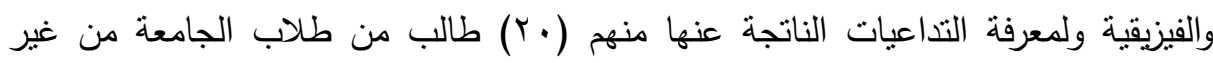

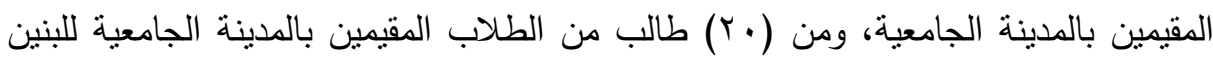

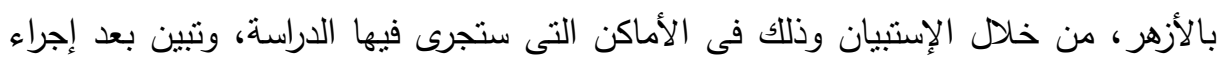
هذه الدراسة الاسنطلاعية أن هناك مشكلات كثيرة وتداعيات كبيرة قد حدثت نتيجة أعمال

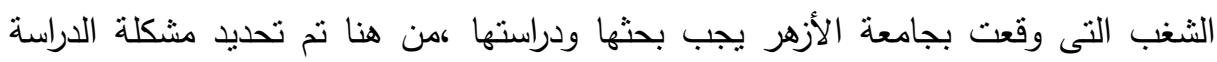

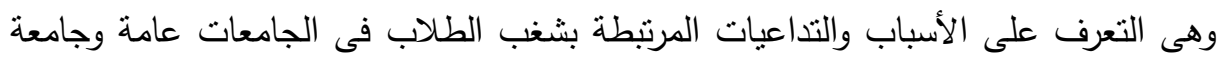
الأزهر خاصة التى تعتبر من أهم الجامعات الاسلامية فى العالم ومعقل الوسطية الدينية المعتدلة، فلماذا وصل الحال ببعض طلابها إلى هذا الحال من حرق وتدمير للمنشأت التهات

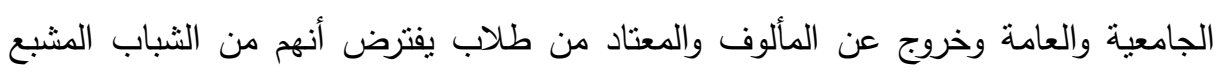
بالأفكار الدينية التى تحض على التسامح والحفاظ على القيم والثثابت الدينية التى نرتفع بالأخلاق إلى أعلى عليين. ويعانى المجتمع فى الفترة الحالية العديد من المشكلات الاجتماعية

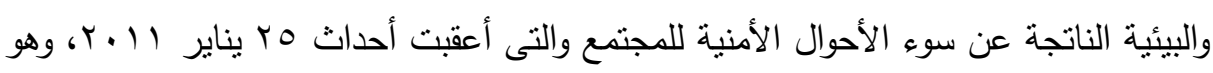

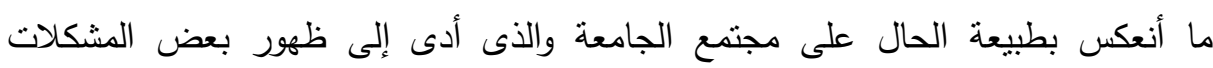
الاجتماعية والفيزيقية المرنبطة بالعنف والثغب بالجامعات عامة وجامعة الأزهر خاصة.

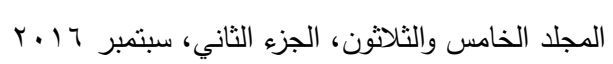




\section{أهمية القواسمة}

تستمد الدراسة أهميتها من عدة عناصر هى: أ. الأهمية العلمية:

البحث عن أسباب وتداعيات مشكلة واقعية تعانى منها الجامعات في الوقت الحالي وهى المى الته

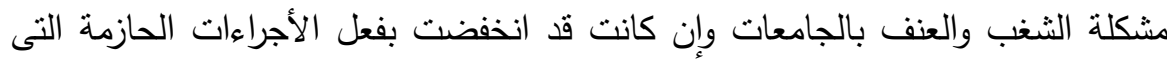

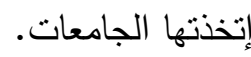
• تحديد أهم التصورات والمقترحات امام متخذى القرار بالنسبة لوجود الحلول الممكنة من

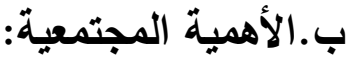

• تتوع المشكلات وإختلاف معدلاتها هى ظاهرة جديرة بالدراسة والبحث لرسم صور واضحة المعالم عن المشكلات الاجتماعبة والفيزيقية المرتبطة بظاهرة الثشب بالجامعات.

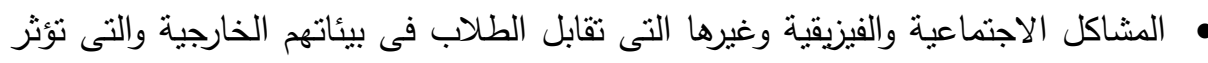
على سلوكياتهم داخل الجامعات والتى تتسبب فى العنف بين الثباب عامة والثباب الجامعى خاصة.

\section{تماولائه الصواسمة}

يتحدد التساؤل الرئيسى للاراسة فى معرفة:

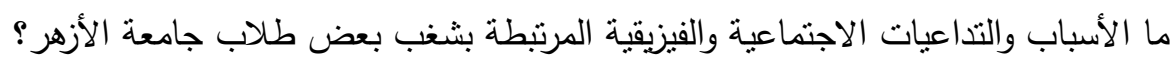
ويتفرع من هذا التساؤل عدة نساؤلات فرعية وهى: ا ـ ما الاسباب الاجتماعية لشغب بعض طلاب جامعة الأزهر من وجهة نظر طلاب الجامعة والمدينة الجامعية الأزهرية؟ r. ما الاسباب الفيزيقية لشغب بعض طلاب جامعة الأزهر من وجهة نظر طلاب الجامعة والمدينة الجامعية الأزهرية؟ مالبن 
حاتم عبد المنعم وآخرون

r. ما التداعيات الناجمة عن شغب بعض طلاب جامعة الأزهر من وجهة نظر طلاب الجامعة والمدينة الجامعية الأزهرية؟ ء. ما التصور المقترح لمنع هذا الثغب او الحد منه مستقبلاً داخل جامعة الأزهر وغيرها من الجامعات المصرية عامة؟

\section{هروغ التراسلا}

• توجد فروق ذات دلالة إحصائية بين أراء طلاب الجامعة و طلاب المدينة الجامعية الأزهربة لهذه الاسباب الاجتماعية.

ه توجد فروق ذات دلالة إحصائية بين أراء طلاب الجامعة وطلاب المدينة الجامعية

$$
\text { الأزهرية لهذه الاسباب الفيزيقية. }
$$

توجد فروق ذات دلالة إحصائية بين أراء طلاب الجامعة و طلاب المدينة الجامعية

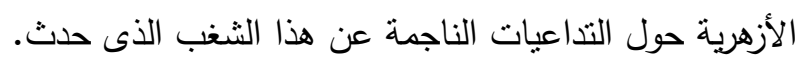

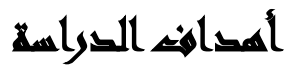

يتحدد الهدف الرئيسى للاراسة فى: الكثف عن الأسباب والتداعيات الاجتماعية والفيزيقية المرتبطة بشغب بعض طلاب جامعة الأزهر . يتفرع من هذا الهدف عدة أهداف فرعية وهى: ا. دراسة الأسباب الاجتماعية لشغب بعض طلاب جامعة الأزهر من وجهة نظر طلاب

$$
\text { الجامعة والمدينة الجامعية. }
$$

r. دراسة الأسباب الفيزيقية لنغب بعض طلاب جامعة الأزهر من وجهة نظر طلاب الجامعة والمدينة الجامعية. r. معرفة التداعبات الناجمة عن شغب بعض طلاب جامعة الأزهر من وجهة نظر طلاب

$$
\text { الجامعة والمدينة الجامعية. }
$$

ع. وضع تصور مقترح لمنع هذا الثغب مستقبلاً او الحد منه داخل جامعة الأزهر.

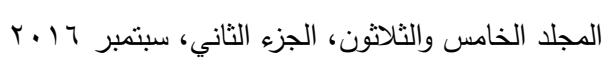




\section{همخاهبه الترواسلة}

مفهوم الثغب وارتباطه بمفاهيم العنف والبلطجة والعدوان:

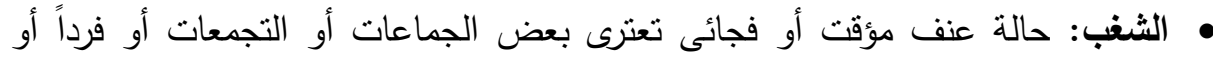

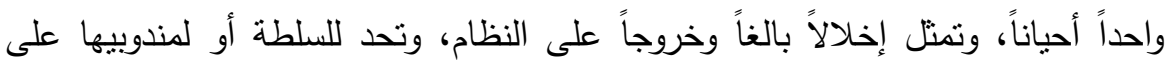

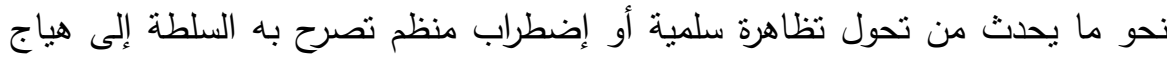

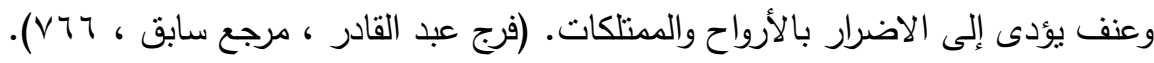
• مفهوم العنف: برى قاموس علم النفس العنف على أنه السلوك الذي بقصد به إيذاء

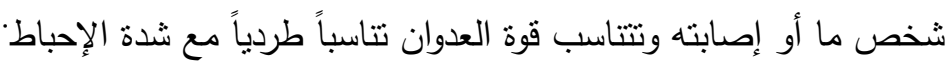

(The new picriomary of psychology N.Y.،1974،P.5) مفهوم الأسباب الاجتماعية والفيزيقية المرتبطة بظاهرة الثغب: الأسباب

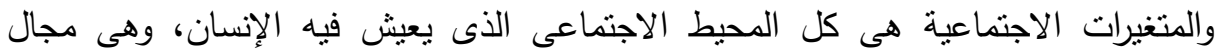

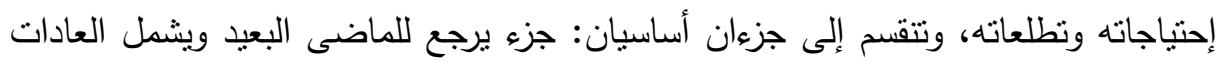

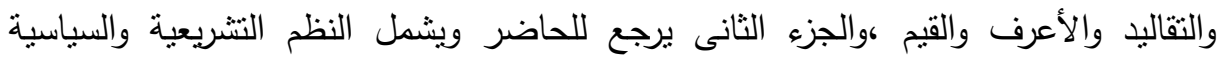

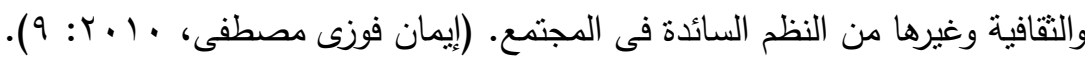

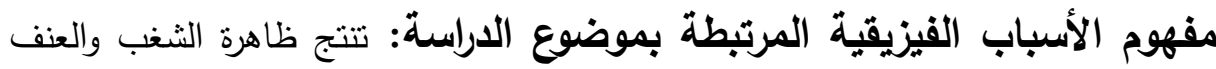
داخل الجامعات من متغيرات ليست اجتماعية او اقتصادية ولكن فيزيقية أيضاً، فالبيئة

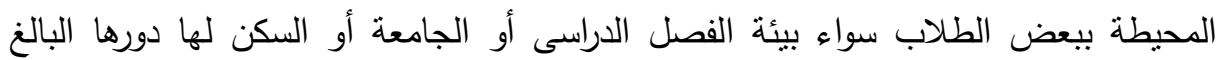
أيضاً فى سعى الطلاب أو الطالبات للثغب والعدوان داخل الجامعات. 
مفهوم الشباب عامة: يعرف معجم ويبستر الثباب علي أنه فترة من الحياة تقع ما بين مرحلة الطفولة ومرحلة النضج أو البلوغ وهي مرحلة مبكرة من النمو والنضج وهي حالة وصفة للتعامل الإنسانى القوى.

مفهوم الشباب الجامعى: طلاب الجامعات هم إحدي الفئات الثبابيه، والتي تتميز بفاعليه النمو، وهي أكثز تلك الفئات تقدماً في عديد من النواحي الفكرية والنفسيه ويعتبر الطلاب بصفة عامة وطلاب الجامعات بصفة خاصة من أهم قطاعات الثباب التي توجه إليها الدول مزيداً من رعايتها وإهتمامها ، فهم يتميزون بكل ما لمرحلة الثباب من خصائص، والجامعات التي يقضي بها الثباب أخطر سنين عمرهم يقع على عاتقها مسئوليات كبيرة، فهي مسئولة عن تتبيت أقدامهم على طريق المعرفة والبحث، وعن إعدادهم للحياة التي سوف يواجهونها عقب تخرجهم من كليات الجامعة ، ومن هنا كانت الجامعة مسئولة عن إتاحة الفرص أمام طلابها وإعدادهم للمشاركة الفعالة في صنع القرارات في مجتمعهم. (المجلس الأعلي للثباب

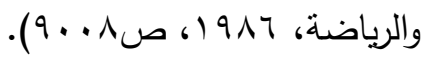

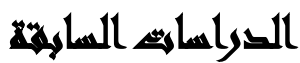

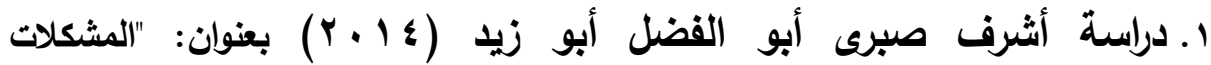
الاجتماعية والفيزيقية المرتبطة بغياب الحرس الجامعى".

أهداف الدراسة: هدفت الدراسة إلى التعرف على المشكلات الاجتماعية والفيزيقية المرتبطة

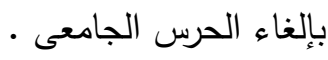

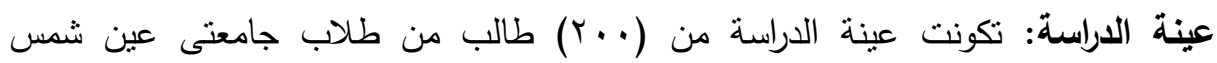
وأسيوط. منهج الاراسة: استخدم الباحث منهج المسح الاجتماعى باستخدام العينة.

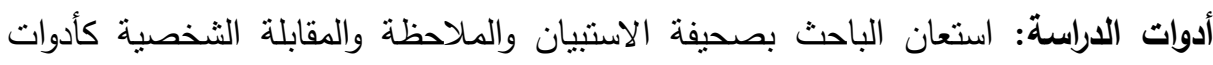
للاراسة، كما استخدم الباحث بعض الاساليب الأحصائية منها اختبار T.test، والتكررات 
نتائج الاراسة: خلصت الدراسة إلى عددآ من النتائج من أبرزها أن هناك فروقآ ذات دلالة احصائية بين أراء الطلاب فى مجتمع الدراسة حول تقييم دور الحرس الجامعى وأهم المشكلات الاجتماعية والفيزيقية المرنبطة بغياب الحرس الجامعى . r. دراسة تهاني محمد عثمان - عزه محمد سليمان (Y. . . ب) بغوان: "العنف

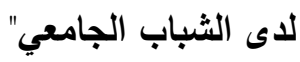

هدف الدراسة: تهدف الدراسة إلى التعرف على طبيعة سلوك العنف لدى الثباب الجامعي

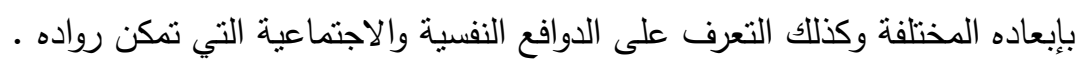

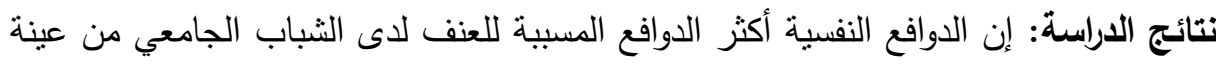

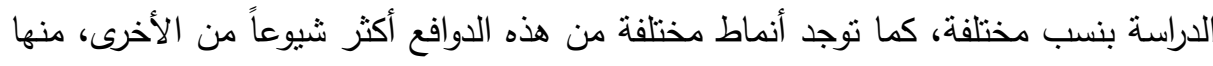
الدوافع الاقتصادية ودوافع إعلامية وتربوية وثقافية.

r. دراسة أحمد العتيق - حاتم عبدا لمنعم (ع 99 1 ) بعنوان: "البيئة والعنف دراسة لبعض الدالات البيئية لاحتمالية السلوك العنيف لاى الثباب المصري" هدف الدراسة: نهدف الدراسة إلى التعرف على طبيعة بعض الدلالات الفيزيقية والاجتماعية لاحتمالية السلوك العنيف لاى عينة من الثباب المصري فى بيئات مختلفة.

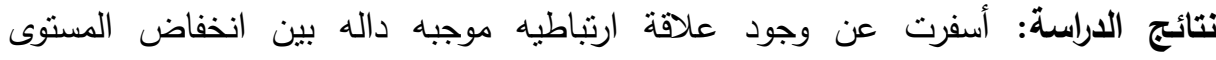
الاقتصادي واحتمالية العنف، فالبيئات المحرومة اقتصادياً تزيد من احتمالية العنف. تعنبر هذه الدراسة من الدراسات ذات الصلة المباشرة بموضوع الدراسة للتعرف على أهم العوامل الاجتماعية و الفيزيقية المسببه للعنف عند الثباب. ع.دراسة:Chang, E. T. (2012) بعنوان: "ثشب لوس انجلوس والمجتمع الأمريكى الكورى" بالولايات المتحدة الأمريكية.

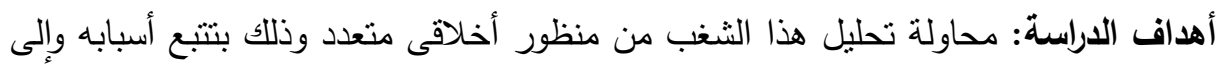
أى مدى ساهمت عدم المساواة العرقية والطبقية فى إنفجار المدينة. ومحاولة دعم الدراسة بالوثائق لأصوات الامريكيون الكوريون الذين عانوا القدر الكبير من الدمار النفسى، ماذا يعنى ذلك الآن بالنسبة للامريكيين الكوريين. 
نتائج الدراسة: توصلت الدراسة أن الاحوال الاجتماعية والاقتصادية والاتجاه الايدولوجى اليمينى كان السبب الرئيسى لشغب لوس انجلوس عام بو 199 م ـ وبينت الدراسة أن تجاهل

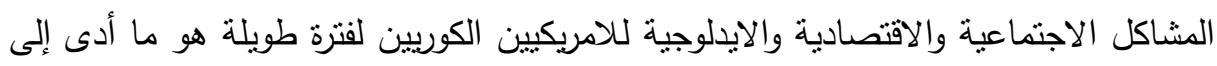
تصاعد هذا الثغب وتتاميه.

\section{الإجباعايت المنهجية}

نوع الدراسة والمنهج المستخدم: تدخل هذه الدراسة فى نطاق الدراسات الوصفية لأنها أنسب الدراسات ملائمة لطبيعة الظاهرة المدروسة. أدوات جمع البيانات:

استمارة استبيان: بالنسبة لأداة الإستبيان المطبقة على عينة الطلاب بجامعة الأزهر والمدينة

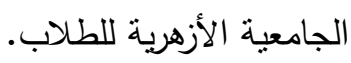
تم تصميم الأداة وفقاً للخطوات الأثية:

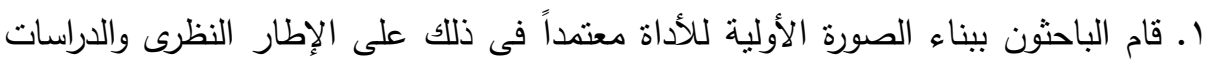

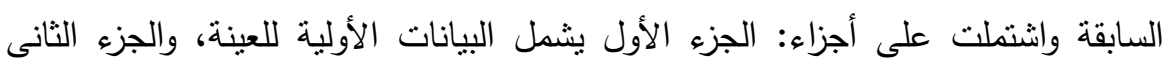

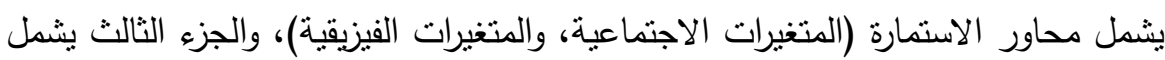

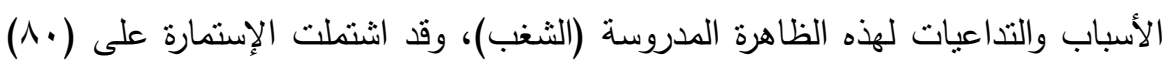
عبارة فى صورتها الأولية. r. بعد عرض الاستمارة على السادة المحكمين من أساتذة علم التربية والاجتماع والبيئة

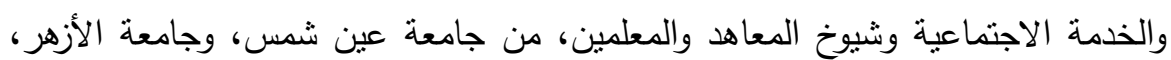
وبعض خبراء التعليم بالأزهر الثريف، وموافقتهم عليها بعد إجراء التعيلات، تم تقنين استمارة الاستبيان وتطبيقها. صدق وثبات الأداة:

أولاً: صدق الاد/ة: حيث قام الباحثون فى اطارمراعاة صدق الأداة بعرض الاستبيان على عدد

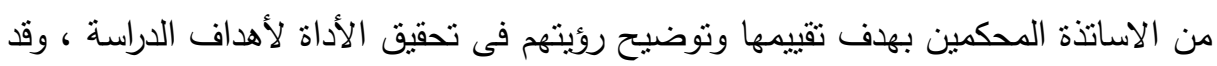

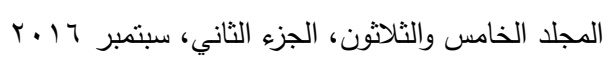


قرر السادة المحكمين أن العبارات الموجودة بالإستبيان ترتبط إرتباطآ بموضوع الدراسة ، وأقروا بصحيتها.

ثانيًا: الثـباتِ: قام الباحثون باختبار مبدئى لأداة البحث للنأكد من ثبات الأداة على مجموعة

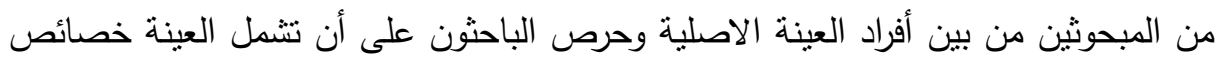

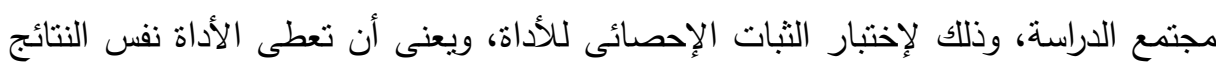
إذا أعبد تطبيقها أكثر من مرة تحت نفس الظروف، ويمكن تقديره بإعادة التطبيق أو التجزئة النصفية، وقد نم تطبيق الاستبيان فى صورته النهائية على عدد (•ع) طالب وطالبة كعينة

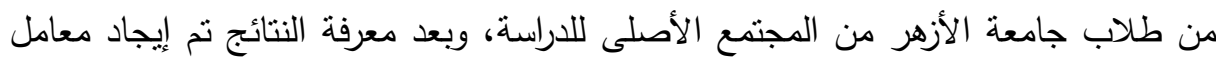
الإرتباط بين الدرجات التى عليها عبارات الاستبيان عن طريق إعادة التطبيق بعد 10 يوم وتم حساب معامل الارتباط بين كل من النطبيقين بإستخدام معامل ارتباط بيرسون، قام الباحثون

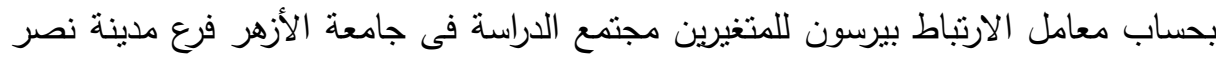

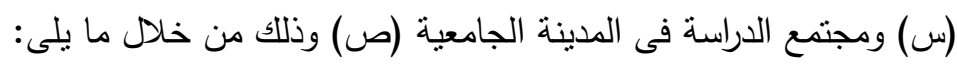

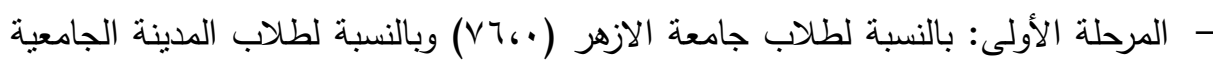
$\cdot(\mathrm{V} 06 \cdot)$

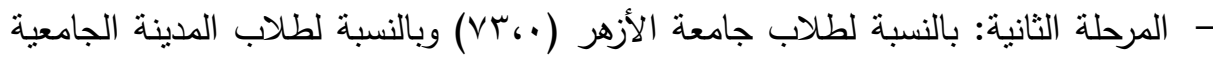
$\cdot\left(\mathrm{v} 0_{6} \cdot\right)$

وكانت الغالبية العظمى من الاستجابات مطابقة للاستنيان الاصلى، وقد أدى ذلك كله إلى الاطمئنان لسلامة أداة البحث وفقاً لدواعى الثبات والصدق الصنات المنهجيين وطبقاً للقواعد العلمية المعمول والمطبقة فى هذا، وبين ذللك مدى امكانية الاعتمادية على نتائج قائمة الاستنيان، ومدى امكانية تعميم نتائجها على مجتمع الدراسة، ونم التأكد من ثبات الأداة.

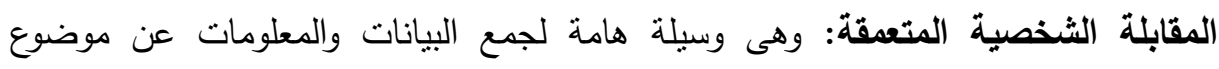
الدراسة وهو الثغب، حيث المقابلة وجهاً لوجه لسبر أغوار المبحوثين، هذا وقد نم الإستعانة

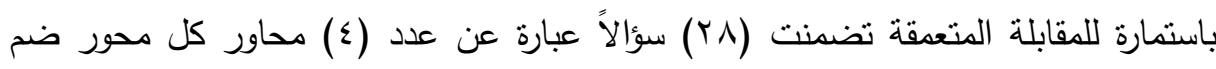

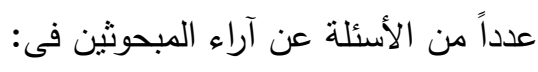


حانم عبد المنعم وآخرون

$$
\begin{aligned}
& \text { ا ـ ما هو الثغب عامة، وماذا يعنى شغب طلاب جامعة الأزهر خاصة؟ }
\end{aligned}
$$

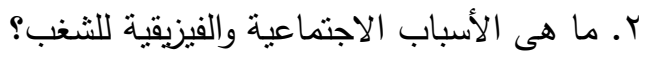

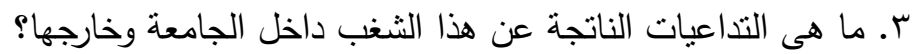

$$
\begin{aligned}
& \text { ـ. ما هى مقترحات المبحوثين لمنع هذا الثغب مستقبلاً } \\
& \text { قد شملت المقابلات الثخصية للاراسة المتعدقة ما يلى: } \\
& \text { - - خمس من مسئولى التعليم الجامعى والخبراء بالتعليم الأزهرى. }
\end{aligned}
$$

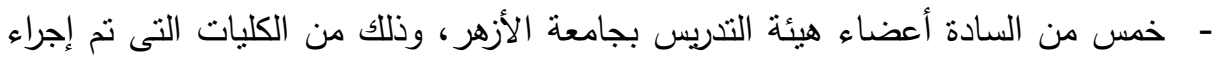

$$
\text { الدراسة بها. }
$$

- خمس من الطلاب للفرقة الثالثة والرابعة من الطلاب فى هاتين الفرقتين من الذين عايشوا

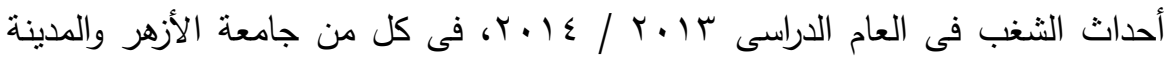

$$
\text { الجامعية فرع مدينة نصر بالقاهرة. }
$$

- خمس من السادة أولياء الأمور للطلاب المقيدين بالفرقتين الثالثة والرابعة بجامعة الأزهر

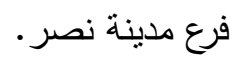

صدق وثبات أداة المقابلة المتعقة: هذا وقد تم عمل صدق وثبات لهذه الأداة بنفس الإجراءات التى تمت بصدق وثبات أداة الاستبيان وبنفس الخطوات المذكور سابقاً، وفيها تم عمل مقابلتين، الأولى نم فيها طرح أسئلة المقابلة على المبحوثين، وبعد 10 يوم تم عمل مقابلة أخرى مع نفس المجموعة للتأكد من صدق وثبات الأداة، ولقد ثيت صدق وثبات هذه الأداة من خلال مقارنة الإجابات فى كل من المفابلة الأولى والثانية وكانت قيمة الثبات كما ولاد يلى:

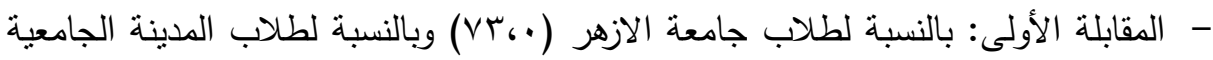
$\cdot\left(\vee \wedge_{6} \cdot\right)$ - المقابلة الثانية: بالنسبة لطلاب جامعة الأزهر (،، (VY) وبالنسبة لطلاب المدينة الجامعية .$(\mathrm{V} 06 \cdot)$

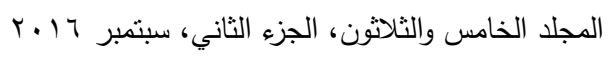


أداة الملاحظة كأدوات لجمع البيانات: والملاحظة إحدى أدوات جمع البيانات من مجتمع البحث حيث إنه عن طريق الملاحظة المقصودة وغير المقصودة يمكن جمع بيانات لا يمكن

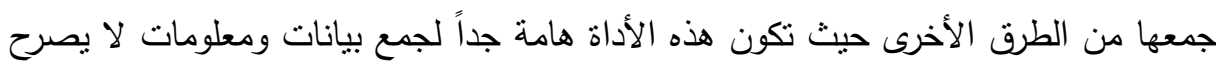

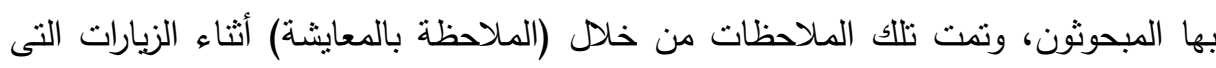
تمت بالجامعة وتم عمل (دليل للملاحظة) لمعرفة ما سيتم ملاحظته أثناء هذه الزيارات، وبعد إنتهاء كل زيارة كان يتم تسجيل ما نت ملاحظته، وتم ملاحظة سلوك المبحوثين من طلاب

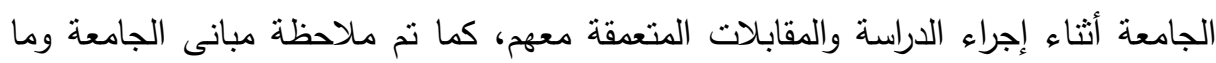
تحتويه من خدمات وملاعب وأنشطة، وملاحظة علاقة الطلاب بأعضاء هيئات التدريس بالجامعة وطريقة التعامل معهم، وملاحظة علاقة الطلاب مع بعضهم البعض داخل واتل أسوار الجامعة وخارجها وذلك أثناء الدراسة الميدانية وتسجيل تلك الملاحظات وتدوينها للاستفادة

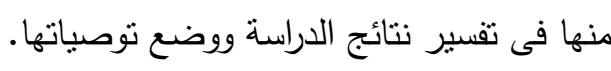

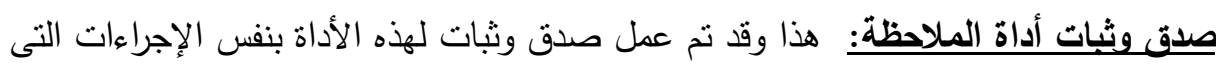

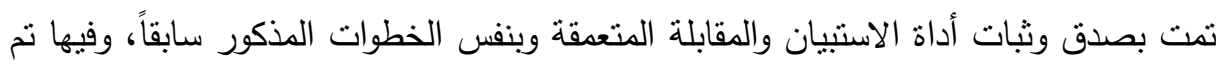
زيارة الأماكن التى تمت فيها الملاحظة مرنين، الأولى تم فيها ملاحظة ما سيتم ملاحظته

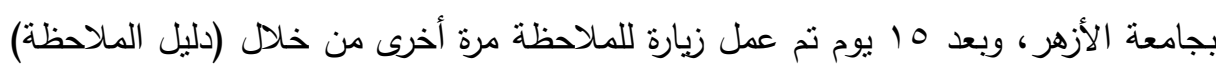

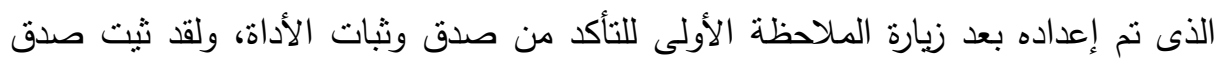
وثبات هذه الأداة من خلال مقارنة الملاحظات التى تمت فى كل من زيارة الاوكى الملاحظة الأولى

$$
\text { والثانية وكانت كما يلى : الماتى }
$$

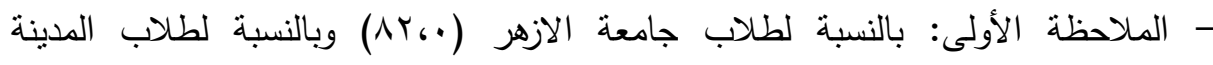

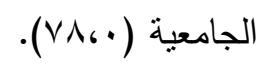

- الملاحظة الثانية: بالنسبة لطلاب جامعة الأزهر (V9، (V9) وبالنسبة لطلاب المدينة

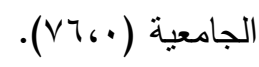


استعان الباحثون ببعض الأساليب الإحصائية منها اختبار .testT، والتكرارات والنسب

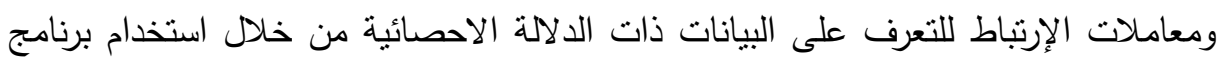
spss

\section{هجالإيت الدوراسة}

المجال الجغرافي: ويقصد بالمجال الجغرافي هو النطاق المكاني لإجراء الدراسة وفى هذه الدراسة سوف يكون المجال الجغرافي لها جامعة الأزهر بفرعها وكلياتها بمدينة نصر ، والمدينة الجامعية الأزهرية للبنين بمدينة نصر ، وهو المكان الذى شهد أحداث العنف الكبيرة والعنيفة. المجال البشرى: ويقصد بالمجال البشرى هو جمهور الدراسة وهم فئات الطلبة الجامعيين

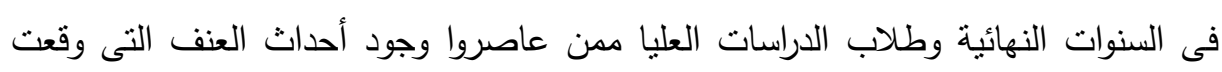

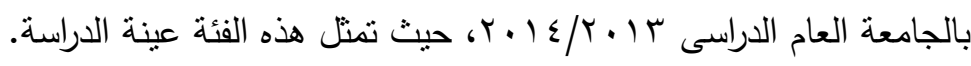
المجال الزمني: استغرقت الدراسة الميدانية قرابة الثلاثة أثهر، ابتداء من شهر يناير

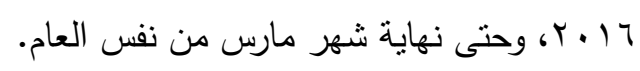

\section{Aصانs}

جدول( ) (1) نوزيع أفراد العينة

\begin{tabular}{|c|c|c|}
\hline النسبة \% & 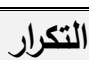 & الإجابة \\
\hline$\%$ & r... & طلاب جامعة الأزهر (بيئة سكن غير جامعى) \\
\hline$\%$ \% & $r \ldots$ & طلاب المدينة الجامعية الأزهرية (بيئة سكن جامعى) \\
\hline$\% 1 \ldots$ & $\varepsilon \ldots$ & الإجمالي \\
\hline
\end{tabular}

وصف الجدول: يثير الجدول رقم (1) إلى توزيع أفراد العينة الإجمالية على الجامعة مجتمع

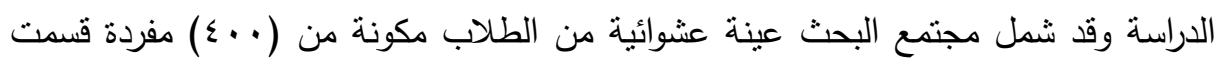

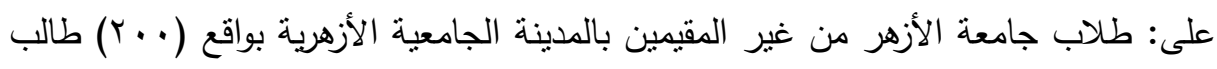

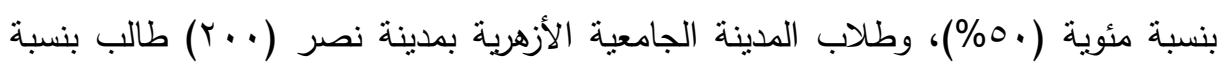

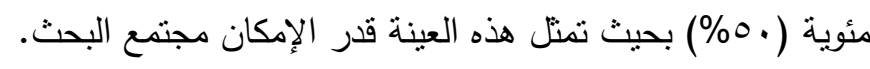

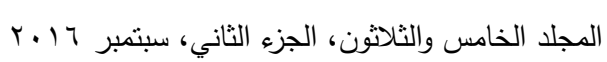


تفسير وتحليل الجدول: وقد حاول الباحثون أن تمثل العينة قدر الإمكان مجتمع البحث من

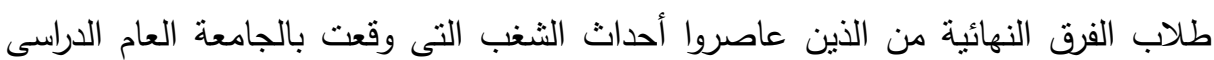

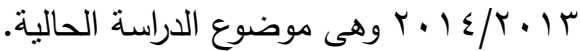

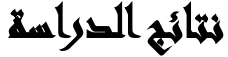

من خلال وصف وتقسير وتحليل الجداول تم استخراج النتائج التالية:

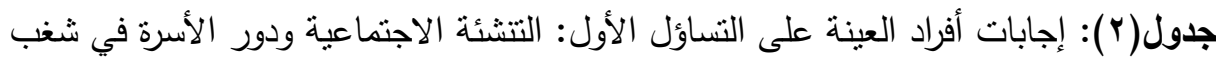

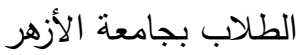

\begin{tabular}{|c|c|c|c|c|c|c|c|c|c|c|c|c|c|c|c|}
\hline \multirow{3}{*}{ Sts } & \multicolumn{7}{|c|}{ 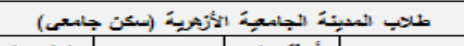 } & \multicolumn{7}{|c|}{ طلاهب جامعة الأزير (مسكن خير جامعى) } & \multirow{3}{*}{ 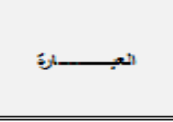 } \\
\hline & \multirow{2}{*}{ الشئوتح } & \multicolumn{2}{|c|}{ لا لواثق } & \multicolumn{2}{|c|}{ أواثق إلهى } & \multicolumn{2}{|c|}{ ئواثق } & \multirow{2}{*}{ النستوسيط } & \multicolumn{2}{|c|}{ لا لواثق } & \multicolumn{2}{|c|}{ كأوبقي إلى } & \multicolumn{2}{|c|}{ ئواثق } & \\
\hline & & $\%$ & $\Delta$ & $\%$ & $\Delta$ & $\%$ & $\Delta$ & & $\%$ & $\Delta$ & $\%$ & $\Delta$ & $\%$ & $\Delta$ & \\
\hline 19.90 & r.. & or & $\cdots$ & rT & $\because$ & 10 & $r$. & $r$ & $\therefore$ & $\cdots$ & $\because$ & Tr & $r \wedge$ & $\therefore$ & 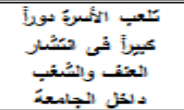 \\
\hline P.A. & $=r$ & $r$. & $\because$ & Tr & $v r$ & $r s$ & $\checkmark \wedge$ & os & $r$ & ru & $r$ & s. & $\leq s$ & ^^ & 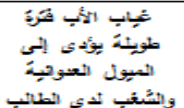 \\
\hline 1sto & 24.0 & ro & $\therefore$ & Tr & $v \leq$ & $T^{\lambda}$ & vis & ov & TT & $\therefore$ & $r$ & $\leq$. & $\leq v$ & is & 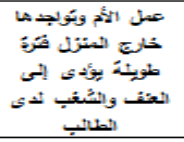 \\
\hline ra.te & $\checkmark \mu$ & 10 & r. & is & in & $\therefore$ & $\cdots$ & 00 & TV & $r s$ & " & $r$ & $\leq 0$ & a. & 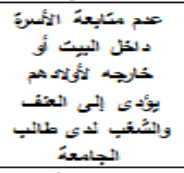 \\
\hline s.tr & $\therefore .0$ & 19 & $r \wedge$ & is & $=\wedge$ & $\therefore$ & $\cdots s$ & vi.o & 'A & Tr & 19 & $T^{\prime} \wedge$ & it & יוז & 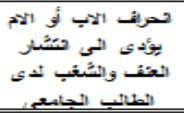 \\
\hline
\end{tabular}

وصف وتفسير وتحليل الجدول: من وصف جدول (Y) السابق يتضح أن هناك فروقاً ذات دلالة إحصائية بين طلاب جامعة الأزهر (بيئة السكن غير الجامعى) وطلاب المدينة الجامعية (بيئة السكن الجامعى) حول الأسباب الاجتماعية المنسبية فى العنف والثغب حيث تباينت

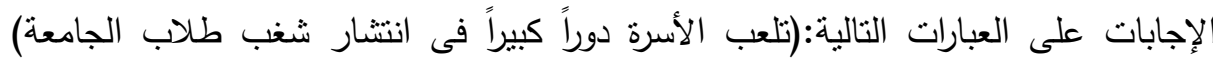


(غياب الأب فترة طويلة يؤدى إلى العنف والثغب لدى الطالب) (عمل الأم وتواجدها خارج

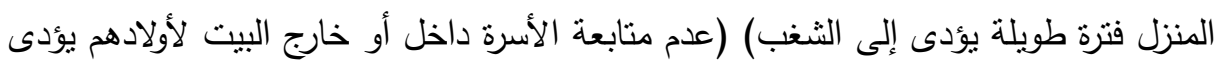

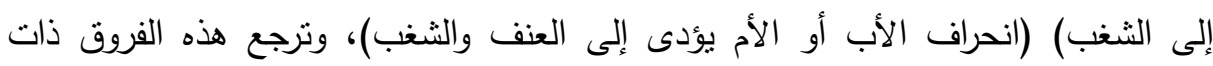

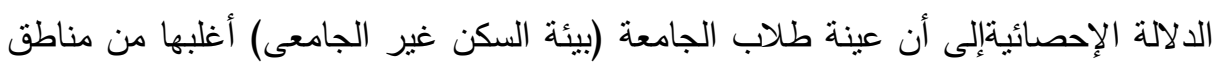

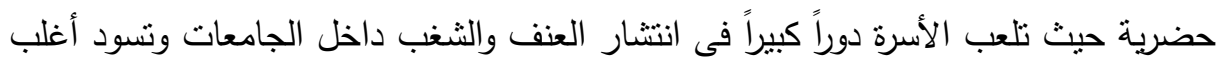

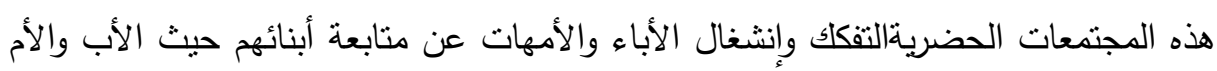

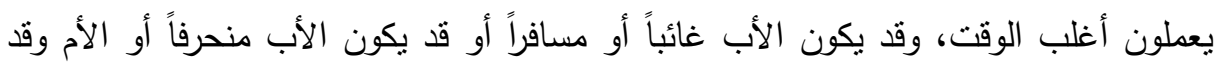

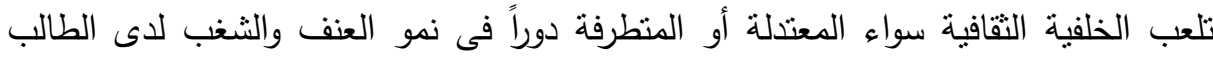
الجامعى، على عكس طلاب المدينة الجامعية الذين يكون أغلبهه من مناطق ريفية منسلحة

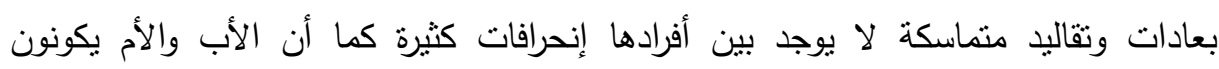
متواجدين أغلب الأوقات بالمنزل وتكون هناك متابعة مستمرة لأبنائهم والروابط الأسرية قوية،

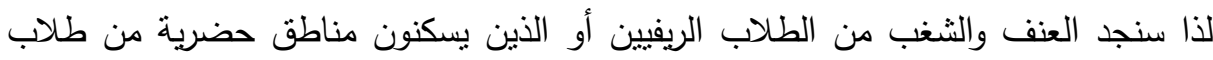
المدينة الجامعية أقل من ذويهم من طلاب الجامعة الغير مقيمين بالمدينة الجامعية الأزهرية.

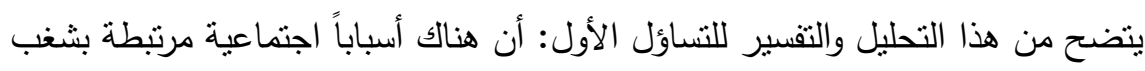

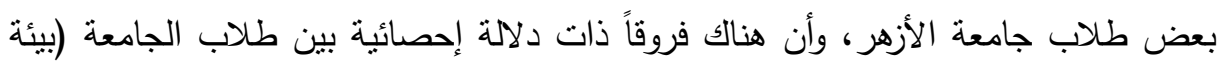

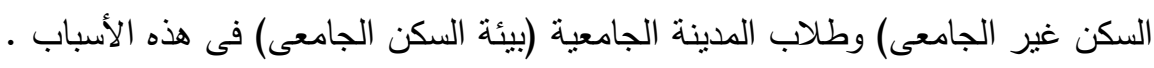

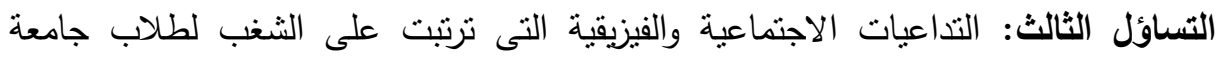
الأزهر. 
جدول (ץ): إجابات أفراد العينة على: التداعيات الاجتماعية والفيزيقية العامة التى ترتبت على الثغب لطلاب جامعة الأزهر

\begin{tabular}{|c|c|c|c|c|c|c|c|c|c|c|c|c|c|c|c|}
\hline \multicolumn{8}{|c|}{ 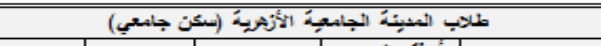 } & \multicolumn{7}{|c|}{ طلاب جاشعة الأزتر (سكن غِر جاسعي) } & \multirow{3}{*}{ المجسرة } \\
\hline \multirow[t]{2}{*}{ كir } & \multirow{2}{*}{ المتوبيَ } & \multicolumn{2}{|c|}{ لانواثق } & \multicolumn{2}{|c|}{ أُواقى إلى حـ } & \multicolumn{2}{|c|}{ ؤراقى } & \multirow{2}{*}{ المبئو } & \multicolumn{2}{|c|}{ لا ؤاقُ } & \multicolumn{2}{|c|}{ 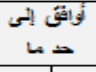 } & \multicolumn{2}{|c|}{ ئواقى } & \\
\hline & & $\%$ & 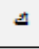 & $\%$ & 4 & $\%$ & 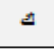 & & $\%$ & $\Delta$ & $\%$ & 4 & $\%$ & 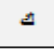 & \\
\hline$A \ldots$ & $\mathrm{rv}$ & 10 & $r$. & 19 & ri & 19 & ita & $\mathrm{va}$ & 4 & in & ro & or & 10 & 17. & 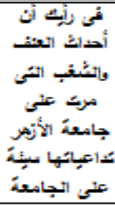 \\
\hline 79.49 & O & iv & $+s$ & $\approx$ & AT & $\leqslant r$ & $\mathrm{As}$ & vv & 17 & $r$ & $r$ & $\leqslant$ & $8 v$ & $1+8$ & 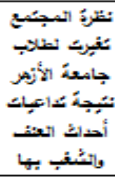 \\
\hline 1.r. & $\therefore 20$ & a & $r$ & 10.0 & 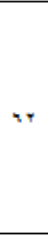 & $r 0.0$ & 1.4 & v. & $v$ & TA & 18 & 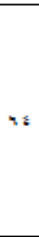 & rv & $\cdots A$ & 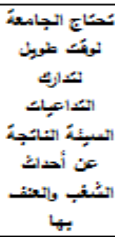 \\
\hline 8.494 & $\because v .0$ & 14 & +4 & $r+$ & 4 & $\therefore$ & , & $v \Psi$ & 10 & $r$. & 78 & $\varepsilon A$ & $\because$ & זיו & 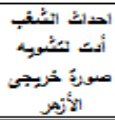 \\
\hline
\end{tabular}

وصف وتفسير وتحليل الجدول: من وصف جدول (ع) السابق يتضح أن هناك فروقاً ذات دلالة إحصائية بين طلاب جامعة الأزهر (بيئة السكن غير ونير الجامعى) وطلاب المدينة الجامعية (بيئة السكن الجامعى) على التساؤل الثالث حول التداعيات الاجتماعية والفيزيقية الناتجة عن شغب بعض الطلاب وذللك للإختيارات (فى رأيك أن أحداث العنف والثغب التى التى التئه

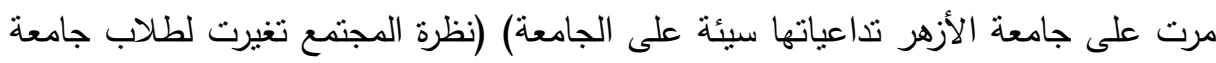
الأزهر نتيجة نداعيات أحداث العنف والشغب بها) وقد تكون تلك الفروق الإحصائية بين طلاب الجامعة وطلاب المدينة الجامعية راجعة إلى أن طلاب الجامعة من غير المقيمين بالمدينة الجامعية يعيشون وسط مجتمعات حضرية تتتاقش وتتبادل الأراء حول تلاك الأحداث 
وما نتجت عنه من تداعيات، كما أن طلاب الجامعة من غير المقيمين بالمدينة الجامعية يجيئون ويذهبون كل يوم إلى الجامعة ويستمعون إلى أراء الناس وتعليقاتهم أثثاء ذهابهم

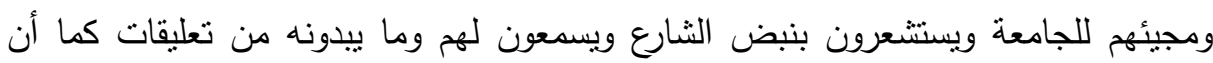
طلاب الجامعة يعيشون نبض العاصمة التى بها مقر الجامعة، عكس طلاب المدينة الجامعية

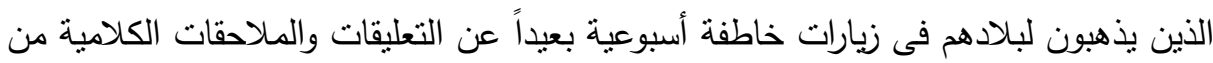
البعض • من هنا كانت الفروق ذات الدلالة الإحصائية. ويتضح من هذا التحليل والتفسير للتساؤل الثالث: أن هناك تداعيات اجتماعية وفيزيقية مرتبطة بشغب بعض طلاب جامعة الأزهر، وأن هناك فروقاً ذات دلالة إحصائية بين طلاب الجامعة (بيئة السكن غير الجامعى) وطلاب المدينة الجامعية (بيئة السكن الجامعى) حول هذه التداعيات. تفسير النتائج: بعض النتائج المستخلصة من الإستنيان الذى نم تطبيقه على الطلاب

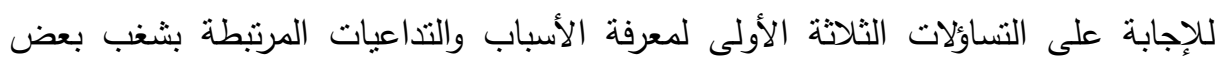
طلاب جامعة الأزهر لكل من طلاب الجامعة من غير ساكنى المدينة الجامعية الأزهرية،

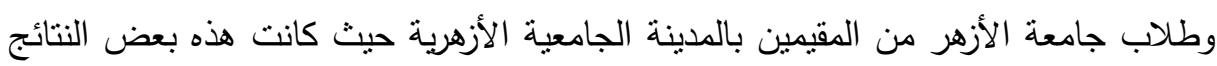
التى تم إستخلاصها من الاستبيان: بالنسبة للتساؤل الأول عن الأسباب الاجتماعية لشغب بعض الأن طلاب جامعة الأزهر من

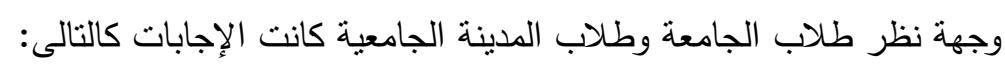

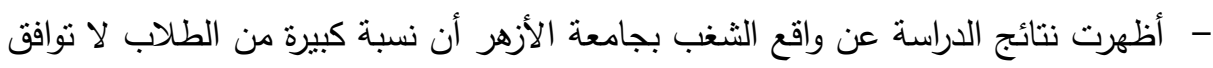

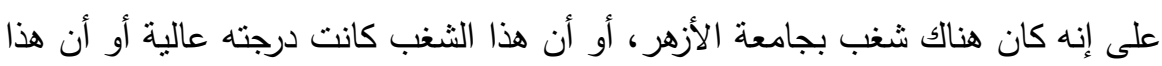

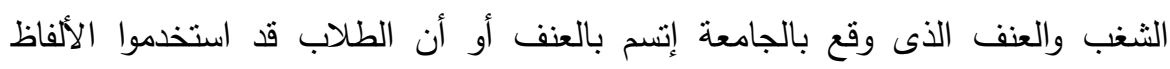

$$
\text { الخارجة أو النابية ضد الجامعة. }
$$

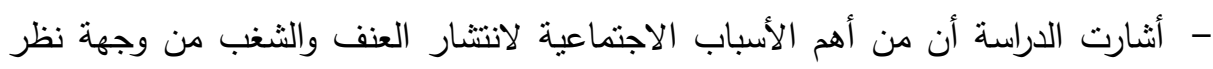

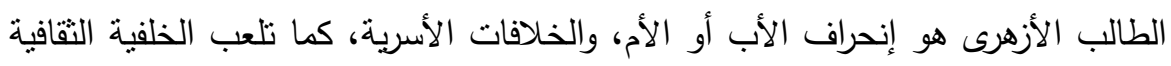

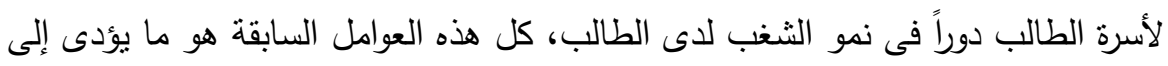

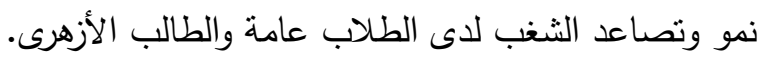


- أثنارت الدراسة إلى أن من بين الأسباب الاجتماعية التى تؤدى إلى الثغب لدى الطلاب

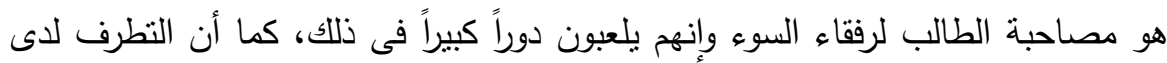
بعض الطلابوتأثز بعض الطلاب بالقائد الطلابى ذو الإتجاهات العنيفة أو المشاغبة

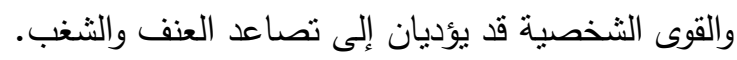
- بينت نتائج الدراسة الميدانية أن التعامل السئ لبعض لئل العاملين والإداريين مع الطلاب

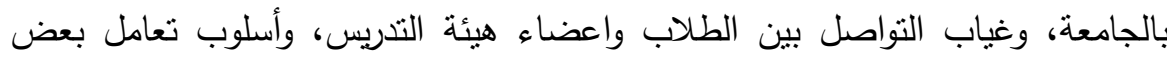

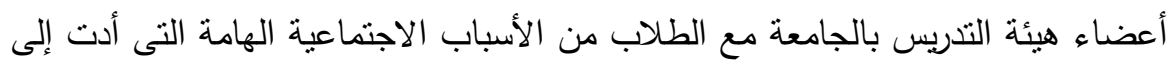
نمو وتصاعد العنف والثخب بجامعة الأزهر.

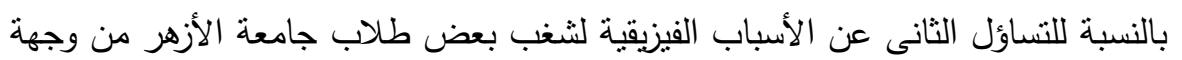

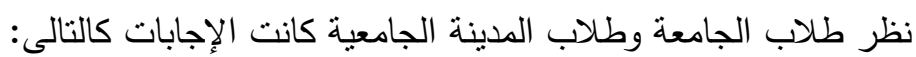

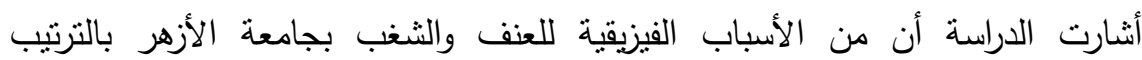

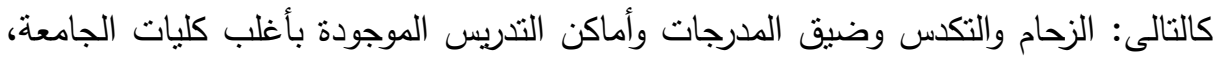
وضعف الإضاءة وعدم وجود الإنارة الكافية ، والضوضاء المنتشرة داخل الجامعة وخارجها، وبعد الجامعة عن أماكن سكن الطلاب بالنسبة للطلاب من غير ساكنى المدينة الجامعية،

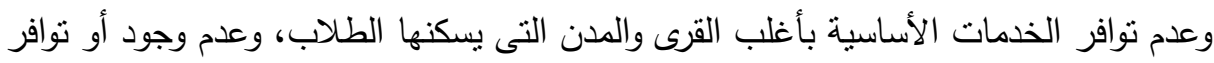
أماكن كافية بالجامعة لممارسة الأنشطة الثقافية والفنية والعلمية بالجامعة، كل هذه الأسباب

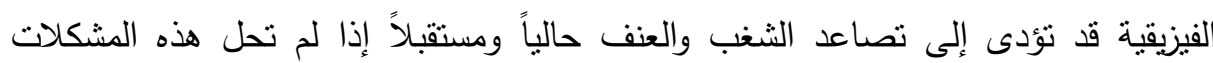
الهامة، وهذه النتائج تنفق ودراسة (أحمد العثيق وحاتم عبد المنعم ؟99 1) حيث بينت الدراسة

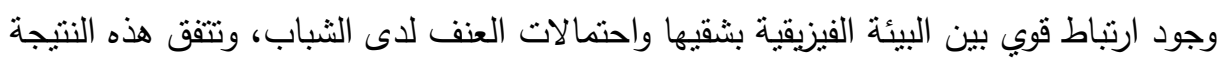

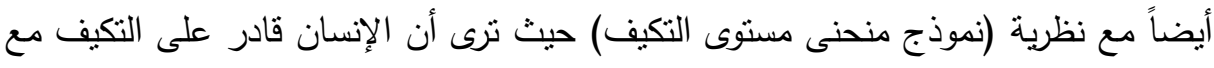
ظروف البيئة حتى ولو كانت سلبية عند مستوى معين ولكن الإثارة المفرطة أو المنخفضة الئهان

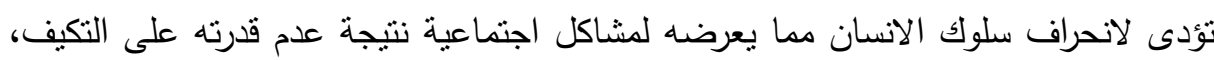

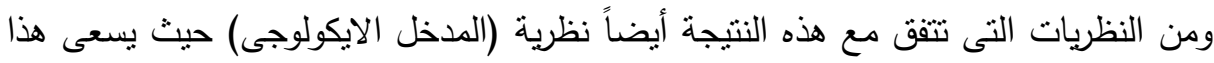


المدخل إلى الكثف عن العلاقة الممكنة بين ظروف البيئة وطريقة سلوك الأفراد فى المنطقة الواحدة والكثف عن صلة الكائن الحى بالبيئة المحيطة ومدى ثأثيرها عليه. الإجابة على التساؤل الرابع عن التصور المقترح لهنع هذا الثغب أو الحد منه مستقبلاً داخل جامعة الأزهر وغيرها من الجامعات المصرية من خلال توصيات الدراسة التالية.

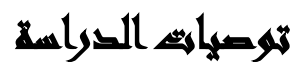

• العمل لوجود لوائح داخلية لضبط سلوك الطلاب داخل الجامعة تكون عادلة وفاعلة.

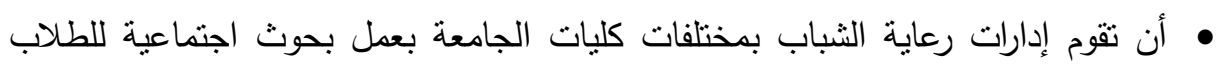

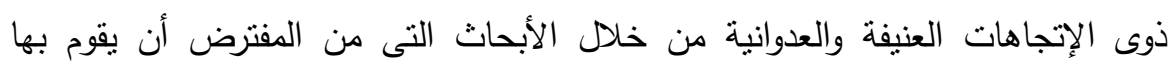

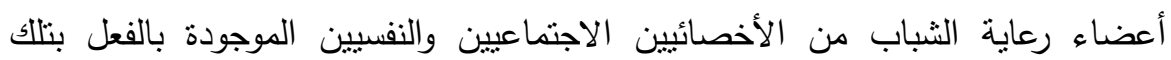
الإدارات حتى يمكن تجنب وجود منل هذه النوعية من الطلاب بقدر الإمكان.

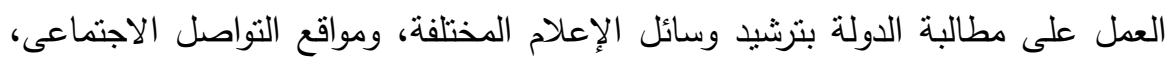
ومراقبة الأفلام السينمائية التى تحض على العنف والارهاب لما لهذه الوسائل من تأثير

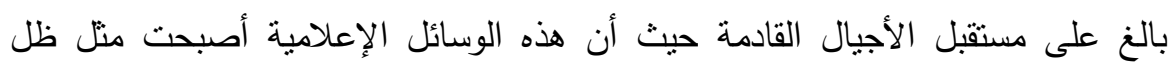
الإنسان معه فى كل مكان وفى أى لحظة، أصبح الثباب يستقى منها معلوماته وتوجهاته لأنه

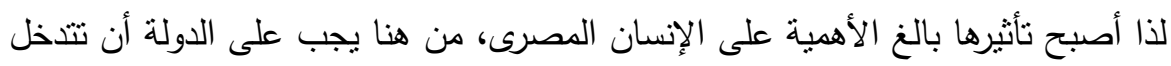

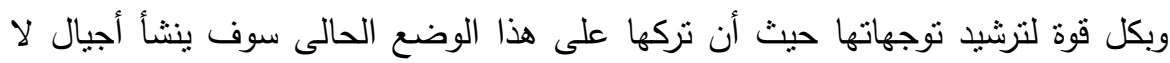

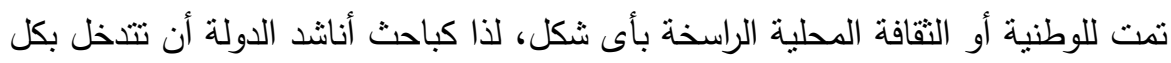

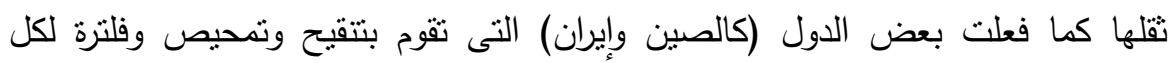

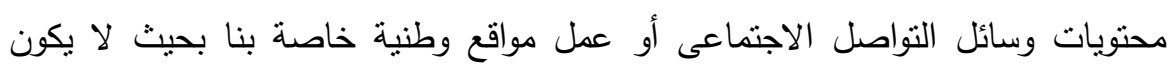
هناك فى هذه الوسائل ما هو موجود الآن من توجهات معادية للاولة الوطنية.

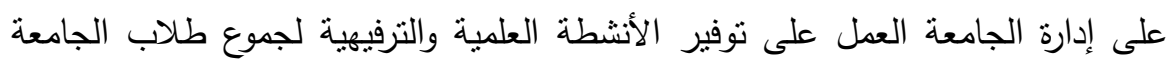
بجميع كليات الجامعة حنى نخفف من العنف والشغب لاى بعض طلاب الجامعة. 


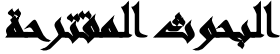

1-دور الحرس الجامعي في الجامعات والمدن الجامعية وتأثثر غيابه على السمات

الاجتماعية والنفسية لاى الطلاب والطالبات بالجامعات والمدن الجامعية.

r- المشاركة السياسية لدى الثباب الجامعي وتأثيرها على التوافق النفسي والاجتماعى لديهم

ودوره فى محافظتهم على الموارد المادية والبشرية للجامعة .

r-مشاركة الطلاب فى الأنشطة الفنية والثقافية والترفيهية بالجامعة ودوره فى التخفيف من فن العنف والعدوان عند الثباب الجامعى. الته.

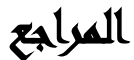

أحمد أبو زيد(9Av (1): البناء الإجتماعى مدخل دراسة الأنساق، المكتب الجامعى الحديث، الأسكندرية

أحمد العتيق، حاتم عبد المنعم(؟99 (1): البيئة والعنف، دراسة لبعض الدالالات البيئية الاجتماعية للسلوك العنيف لدى الثباب المصري، الإسكندرية، دار المعارف لإلفية

$$
\text { الجامعية }
$$

أحمد محمد السنهورى وآخرون(Y99 (1)): الخدمة الإجتماعية والبيئة، دار السعيد للطباعة، القاهرة

إكرام سيد غلاب(V . . ץ): أساسيات فى مناهج البحث الإجتماعى، الدار العلمية للطباعة، دمنهور

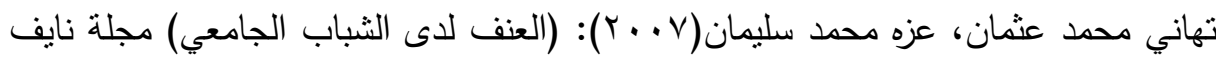
العربية للعلوم الأمنية عزية

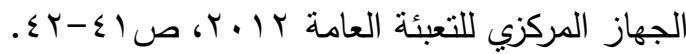

Altieri, M. A. (1993): "Ethnoscience and Biodiversity" Key Elements in the Design of Sustainable Post Management Systems for Small Farmers in Developing Counteries.'Agriculture Ecosystems-and Environment. Vol.46, PP.257-265.

Bagdasarova, N. and Ivanov, A. (2009): "Private tutorin in Kyrgyzstan" In: 1.silova (ed)، Private Supplementary tutoring in Central

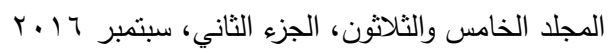


حانم عبد المنعم وآخرون

Asia: new Opporunities and burdens (PP.119-142).Paris: HEP- UNESCO.

Behnke, R. (1994): "Natural Resource Management in Pastoral Africa" Development-Policy-Review. Vol.12, No.1. PP. 5-27.

Brill, N. (1990): Working with People The Helping process` New York‘ longman. P.14.

Buchmann (2002): "Getting ahead in Kenya; Social Capital, Shadow Education and achievement "In;B.Fuller، E.Hannum (Eds), Schooling and Social Capital in diverse Cultures (PP.133159). Amsterdam; JAI Press.

Shrake, Eunai Kim [Ed]; Chen، Edith Wen-Chu [Ed]. (2012). Asian Pacific Chang، Edward T. American experiences: Past، present، and future. (pp. 335-345). viii، 412 pp. Dubuque، IA، US: Kendall Hunt Publishing Company; US. 
مجلة العلوم البيئية

معهد الدراسات والبحوث البيئية - جامعة عين شمس البرس

\title{
SOCIAL AND PHYSICAL REASONS AND \\ CONSEQUENCES ASSOCIATED WITH SOME \\ STUDENTS RIOT OF AL-AZHAR UNIVERSITY - A \\ COMPARATIVE STUDY BETWEEN UNIVERSITY \\ STUDENTS AND THE RESIDENT STATUS \\ STUDENTS
}

\author{
Ahmed, H. A. ${ }^{(1)}$; Al-Gazar, O. I. ${ }^{(2)}$; Ibrahim, Reem, A. ${ }^{(3)}$ \\ and Mohamed, A. S. ${ }^{(4)}$
}

1) Institute of Environmental Studies and Research, Ain Shams University 2) Faculty of Education, Al-Azhar University 3) Faculty of Education, Helwan University 4) Al-Azhar

\begin{abstract}
The current study drives at exploring the social and physical reasons and consequences associated with students' riot of Al-Azhar university، comparing as well the university students (as an example of non-resident status students) to resident status students of Al-Azhar university. The study sample consists of (400) regular enrolled students for the academic year (2015/2016). It is divided equally into (200) resident status students and (200) non-resident students.

The study uses the descriptive (qualitative) method using the social survey of random sample. The study is also an analytical case study as a tool for collecting data from research population, using also in-depth interviews. the study tools are reflected in: questionnaire form, observation and personal interviews. The researcher counts on some statistical approaches such as: T.Test, frequencies, percentages، and coefficient correlations.
\end{abstract}




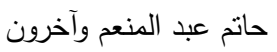

The study extracts several results as follows: there are significant statistical differences between students' points of view (study sample) regarding social and physical reasons and consequences for riot caused by academic delay and parents' maltreatment. Resident status students think that riot is the low-level of education and maltreatment of those in charge of the Resident Status of the university. In addition, the injustice of some of the teaching staff members and professors in correcting students' answer papers, their low scores in exams they don't deserve after exerting lots of efforts in their educational subjects as they perceive it. All these reasons gathered to create violence or riot in the ancient Azhari university.

The study show that there are several consequences resulted in riot has occurred in the university, including change of society's point of view to students and graduates of Al-Azhar university and change of treatment of those in charge of of the university and the teaching staff members and workers to the worst. Security men also play a critical role in their exaggerated strictness with students during going in and out from the university campus which make them feel aggrieved and oppressed.

The study recommends holding meetings and discourses between those in charge of the university and members of the teaching staff for alleviating severity of these reasons have caused riot and their consequences. 